\title{
The Effects of an Educational Program on Using Dietary Approach to Reduce High Blood Pressure in Khartoum State, Sudan (2015)
}

\author{
Ibrahim Abbakr Ibbrahim \\ Faculty of Nursing, Umm Al-Qura University, Makkah, KSA \\ Email: ibrahimabbakr@gmail.com
}

How to cite this paper: Ibbrahim, I.A. (2019) The Effects of an Educational Program on Using Dietary Approach to Reduce High Blood Pressure in Khartoum State, Sudan (2015). Open Journal of Nursing, 9, 541-560.

https://doi.org/10.4236/ojn.2019.95046

Received: March 22, 2019

Accepted: May 27, 2019

Published: May 30, 2019

Copyright $\odot 2019$ by author(s) and Scientific Research Publishing Inc. This work is licensed under the Creative Commons Attribution International License (CC BY 4.0).

http://creativecommons.org/licenses/by/4.0/

\begin{abstract}
Background: Sudan is considered one of the leading countries in Africa for the prevalence of hypertension. However, a proper national registry on hypertension is not available in Sudan and evaluation studies are rarely done. Nevertheless, a recent study showed an increase in incidences of hypertension in Sudan. The DASH (Dietary Approaches to Stop Hypertension) diet, which is rich in fruits, vegetables, and low-fat dairy foods, significantly lowers the blood pressure. Objective: To examine the effectiveness of dietary approach to reduce hypertension (DASH) in the reduction of high blood pressure among hypertensive patients. Design: This research is an interventional case control community base study which was carried in 100 patients; 69 females and 31 males were selected by convenient sampling method. They were divided into two groups by simple random sampling 50 patients assigned in the case group and 50 in control group then followed every one separately for ten months. Intervention: The case group were taught individually about dietary approach to reduce hypertension DASH and each participant in case group possessed a book for teaching program to eat food low in saturated fat, cholesterol, total fat and emphasize fruits, vegetables, and fat-free or low-fat milk and milk products; then blood pressure measured monthly for both case and control group for ten month. Result: The study shows decrease in systolic blood pressure among patients who followed dietary approach and received teaching significantly in 4th month $(\mathrm{p}=0.032)$ and diastolic blood pressure became significantly in 6th month $(\mathrm{p}=0.032)$ and became more significant in next four months without change in control group. Conclusion: The study concluded that a diet rich in fruits, vegetables, and low-fat dairy foods, reduced saturated and total fat can substantially lower blood pressure. Recommendation: It is necessary to apply a nutritional approach among all hypertensive patients because it could minimize both the healthcare workload
\end{abstract}


and the money cost for therapy in clinical area.

\section{Keywords}

Patient, Hypertension, Dietary Approach

\section{Introduction}

Blood pressure can be unhealthy even if it stays only slightly above the normal level of 120/80 mm.Hg. High blood pressure affects about 50 million or 1 in 4 adult Americans. High blood pressure is especially common among African Americans who tend to develop it at an earlier age and more often than Whites. It is also common among older Americans-Individuals with normal blood pressure at age 55 have a 90 percent lifetime risk for developing hypertension [1].

Worldwide, raised blood pressure is estimated to cause 7.5 million deaths, about $12.8 \%$ of the total of all deaths. This accounts for 57 million disability adjusted life years (DALYs) or 3.7\% of total DALYs [2]. Raised blood pressure is a major risk factor for coronary heart disease and ischemic as well as hemorrhagic stroke. Blood pressure levels have been shown to be positively and continuously related to the risk of stroke and coronary heart disease [2]. In some age groups, the risk of cardiovascular disease doubles for each increment of $20 / 10 \mathrm{~mm} \cdot \mathrm{Hg}$ of blood pressure, starting as low as $115 / 75 \mathrm{~mm} \cdot \mathrm{Hg}$. In addition to coronary heart diseases and stroke, complications of raised blood pressure include heart failure, peripheral vascular disease, renal impairment, retinal hemorrhage and visual impairment. Treating systolic blood pressure and diastolic blood pressure until they are less than $140 / 90 \mathrm{~mm} \cdot \mathrm{Hg}$ is associated with a reduction in cardiovascular complications [2].

As of 2000 , nearly one billion people or $\sim 26 \%$ of the adult population of the world had hypertension. It was common in both developed (333 million) and undeveloped (639 million) countries [3]. However, rates vary markedly in different regions with rates as low as $3.4 \%$ (men) and $6.8 \%$ (women) in rural India and as high as $68.9 \%$ (men) and $72.5 \%$ (women) in Poland [4]. In Europe hypertension occurs in about $30 \%-45 \%$ of people as of 2013 [5]. In 1995 it was estimated that 43 million people in the United States had hypertension or were taking antihypertensive medication, almost $24 \%$ of the adult United States population [6]. The prevalence of hypertension in the United States is increasing and reached 29\% in 2004 [7]. As of 2006 hypertension affects 76 million US adults (34\% of the population) and African American adults have among the highest rates of hypertension in the world at $44 \%$ [8]. It is more common in black, Filipinos, and Native Americans and less in white and, Mexican Americans, rates increase with age, and is greater in the southeastern United States [3]. Hypertension is more common in men (though menopause tends to decrease this difference) and in those of low socioeconomic status.

Although hypertension remains more prevalent in economically developed 
countries (37.3\%) compared to developing nations (22.9\%), it is a much bigger problem in developing countries, in terms of actual numbers, awareness, treatment and complications, prevalence is also rising more rapidly across developing countries where it is estimated that three quarters ( 1.17 billion) of cases will exist by 2025 [3]. Recent studies from African countries have shown prevalence being $15 \%-50 \%$, and higher in urban than in rural populations [9].

In Khartoum 1990 estimated prevalence was found to be $7.5 \%$, with a positive correlation between blood pressure and age, weight, body mass index and duration of urban residence [10].

More recently, data from the Sudan Household Survey in 2006 of chronic disease risk factors in Khartoum found hypertension prevalence to be $20.1 \%$ and $20.4 \%$ respectively [11]. Of concern are the poor rates of knowledge and control of hypertension in sub-Saharan Africa. A systematic review of 25 studies across the region found that less than $40 \%$ of people knew they were hypertensive, less than $30 \%$ were on treatment and less than $20 \%$ of those on treatment had a controlled blood pressure [12].

In Kassala, Eastern Sudan, knowledge of hypertension was poor, compliance with antihypertensive drug treatment was $59 \%$, and $36.8 \%$ said they could not afford to buy the drugs they were prescribed [13]. A recent article in the Sudan Tribune warned that rising levels of non-communicable diseases and an aging population will have major implications for health and socio-economic development in the world's newest nation [14].

According to the latest WHO data published in April 2011, Hypertension Deaths in Sudan reached 12,281 or 3.33\% of total deaths. The age adjusted Death Rate was 67.67 per 100,000 of population ranks Sudan number 17 in the world [15].

This study aimed to use another method to reduce high blood pressure (hypertension) which is known as dietary approach to stop hypertension (DASH) in order to decrease the prevalence of hypertension. The DASH eating plan is rich in fruits, vegetables, fat-free or low-fat milk and milk products, whole grains, fish, poultry, beans, seeds, and nuts. It also contains less salt and sodium; sweets, added sugars, and sugar-containing beverages; fats; and red meats. This heart-healthy way of eating is also lower in saturated fat, trans fat, and cholesterol and rich in nutrients that are associated with lowering blood pressure-Mainly potassium, magnesium, and calcium, protein, and fiber [16].

\subsection{Statement of the Problem}

The mortality due to hypertension (HTN) account for $20 \%-50 \%$ of all deaths and the projected number of adults who will have hypertension by 2025 is 1.56 billion, it was reported that the highest prevalence of HTN was in Africa and approximately $80 \%$ of deaths in low-middle income countries were due to commonest complication of HTN is cardiovascular disease. All published studies about hypertension in Sudan targeted small scale studies for different specific population, a study in some referral clinics in Khartoum had shown cardiac, 
neurological and renal symptoms were the major presenting complaints [17]. Hypertension was detected in $18.2 \%$ of the population with different occupations in Khartoum State and $10.2 \%$ were known hypertensive. School based study in Khartoum State has shown $4.9 \%$ of obese primary school children in age group 6 - 12 years were hypertensive. Passive screening program in Northern state in Sudan has shown $28.5 \%$ of village inhabitants were known hypertensive and $39.6 \%$ were having hypertension after screening. Local studies were conducted in urban settings rather than rural and showed high prevalence of target organ damages and almost no data was available from rural areas in states [17].

A study was conducted into blood pressure in a sample of 510 urban Sudanese working in the post office in Khartoum. The mean age was 35 years and $65 \%$ of the workers came from Northern Sudan. Cigarette smoking and consumption of alcohol were commonest amongst those from Southern Sudan. Both systolic and diastolic BPs rose with age. The prevalence of hypertension $(140 / 90 \mathrm{~mm} \cdot \mathrm{Hg}$ or greater) was $7.5 \%$. BP levels in this study were lower than those reported in $\mathrm{Ni}$ gerians or blacks in the Caribbean or the United States. There was a significant positive correlation between systolic blood pressure and diastolic blood pressure and age, weight, body mass index and duration of residence in the city. These data confirm that hypertension is becoming an important health problem in Sudan.

In 2010, about 58.6 million persons or 25.1 percent of adults age 18 and older were treated for hypertension. Direct medical spending to treat hypertension totaled $\$ 42.9$ billion in 2010 , with almost half ( $\$ 20.4$ billion) in the form of prescription medications. Annual expenditures for those treated for hypertension averaged $\$ 733$ per adult in 2010 (Agency for Healthcare and Research Quality April 2013).

\subsection{Justification}

o In spite of the availability of the hypertension treatment, the incidence and mortality rate of hypertension is rising up according to many studies.

o Hypertension medications are very costive in comparing with life-style changes (DASH).

o Dietary approach to reduce hypertension (DASH) is cheaper and more available than clinical management.

o This means that the drug alone is not enough to control and prevent complications of hypertension. So orientations of the patient about additional method of control blood pressure like dietary approaches to reduce hypertension DASH is more necessary to be applied.

o No previous study was done.

\subsection{Research Question}

This study sets out to answer the following question:

Can dietary approach and education program contribute to reduction of high blood pressure? 


\subsection{Objectives}

\subsubsection{General Objective}

To study the effectiveness of an educational program using dietary approach to reduce high blood pressure among hypertensive patients in Khartoum state.

\subsubsection{Specific Objectives}

1) To apply dietary approach and an educational program for hypertensive patient in the study group.

2) To assess knowledge of hypertensive patients towards management of hypertension before intervention.

3) To compare the control of BP among patients using antihypertensive drugs plus dietary approach with those using antihypertensive drugs alone.

\section{Methodology}

\subsection{Study Design}

The study was an interventional case control community-based study. The case was received antihypertensive drug plus using dietary approach to stop hypertension (DASH) and the control received only antihypertensive drug.

\subsection{Study Area}

Khartoum is one of Sudan state. Although it is the smallest state in terms of area $\left(22,142 \mathrm{~km}^{2}\right)$, it is the most populated state $(5,274,321$ in 2008 census). It contains the country's largest city in terms of population, Omdurman, and the city of Khartoum, which is the capital of the state as well as the national capital of Sudan. The capital city contains offices of the state, governmental and non-governmental organizations, cultural institutions, and the main airport.

The state lies between longitudes $31.5^{\circ}$ to $34^{\circ} \mathrm{E}$ and latitudes $15^{\circ}$ to $16^{\circ} \mathrm{N}$. It is surrounded by River Nile State in the north-east, in the north-west by the Northern State, in the east and southeast by the states of Kassala, Gedaref and Gezira, and in the west by North Kurdufan.

\subsubsection{Administrative Divisions}

The state is geographically divided into blocks (or clusters), which are further subdivided into localities. There are a total of three blocks and seven localities.

\subsubsection{First Block: Jebel Aulia Locality and AL Khartoum Locality}

This starts from the Morgan the confluence of the Blue Nile and White Nile, and extends southward between them to the boundaries of Gezira state. The block is characterized by Sundus and Soba agricultural schemes in both the Gebel Auliaand Khartoum localities, along with numbers of livestock, poultry, fishing, and fodder production projects, as well as vegetable and fruit farms.

\subsubsection{Second Block: Khartoum North and Sharq An-Nil Locality} (Blue Nile)

This is the northern block, between the Blue Nile and the River Nile. The largest 
town in this block is Khartoum North. There are many agricultural projects, such as the Soba East and Seleit projects, and the largest dairy project in the state, the Kuku village project. The block also includes the largest industrial areas in Sudan. Omdurman Locality, Ombadda Locality (Um Badda) and Karari Locality (Karari).

For further clarification see Figure 1.

\subsubsection{Health Services and Socioeconomic Status}

The Khartoum state populations are composed of different tribes of Sudan which arrived at it from north, south, east and western of Sudan and the socioeconomic status is varies from low, moderate and high. The people in Khartoum are employed in different jobs: Governmental job, labor, free business, etc.

The Khartoum state populations receive their medical health services from 48 public health centers which are divided into 16 public hospitals in Khartoum, 19 in Omdurman and 18 in Khartoum Bahari in addition to private clinics and hospitals.

\subsection{Study Population}

Hypertensive patients hospitalized and none hospitalized (out-patient clinic) and in the community without hypertension complication.

\subsection{Sample Size and Sample Procedure}

The total number of participant were 100 hypertensive patients divided into two groups, 50 person case and 50 person as control that is selected by a non-randomized method called convenience sample method.

Convenience sampling or accidental sampling is a type of non-probability sampling which involves the sample being drawn from that part of the population which is close to hand it has several advantages like expedited data collection, ease of research, readily available and cost-effective.

The researcher screened 130 potential participants by direct interview. The

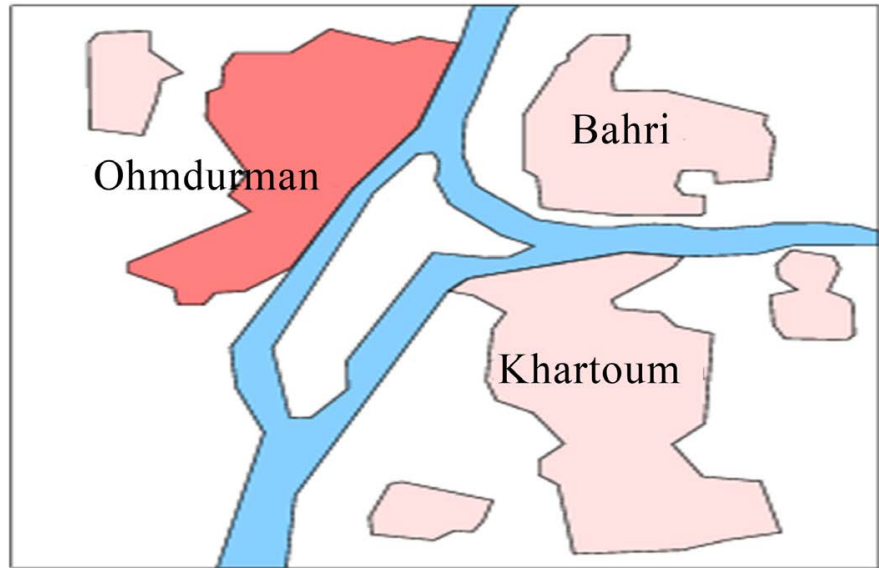

Figure 1. Shows the Khartoum state map and location of the main city Khartoum, Bahri and Omdurman. 
study excluded 30 potential participants via direct intervention, 10 because of significant heart disease (heart failure and ischemic heart diseases) informed by patients, 9 because of refusal to participate in the study and 11 excluded due to renal disease (patients told). We obtained verbal consent from 100 potential participants; these 100 patients are divided into two groups, 50 eligible men and women were assigned to be intervention group while 50 patient men and women were assigned to be control group of the study (50 cases, 50 controls). This was done by simple random sampling.

During study 5 patients dropped from study ( 3 of them didn't want to continue more in the study and loss contact for 2 patients) and 45 patient completed as a case (intervention group). From the control group 7 patients dropped from study due to loss of contact and 43 patients completed as control group.

For further clarification see Figure 2.

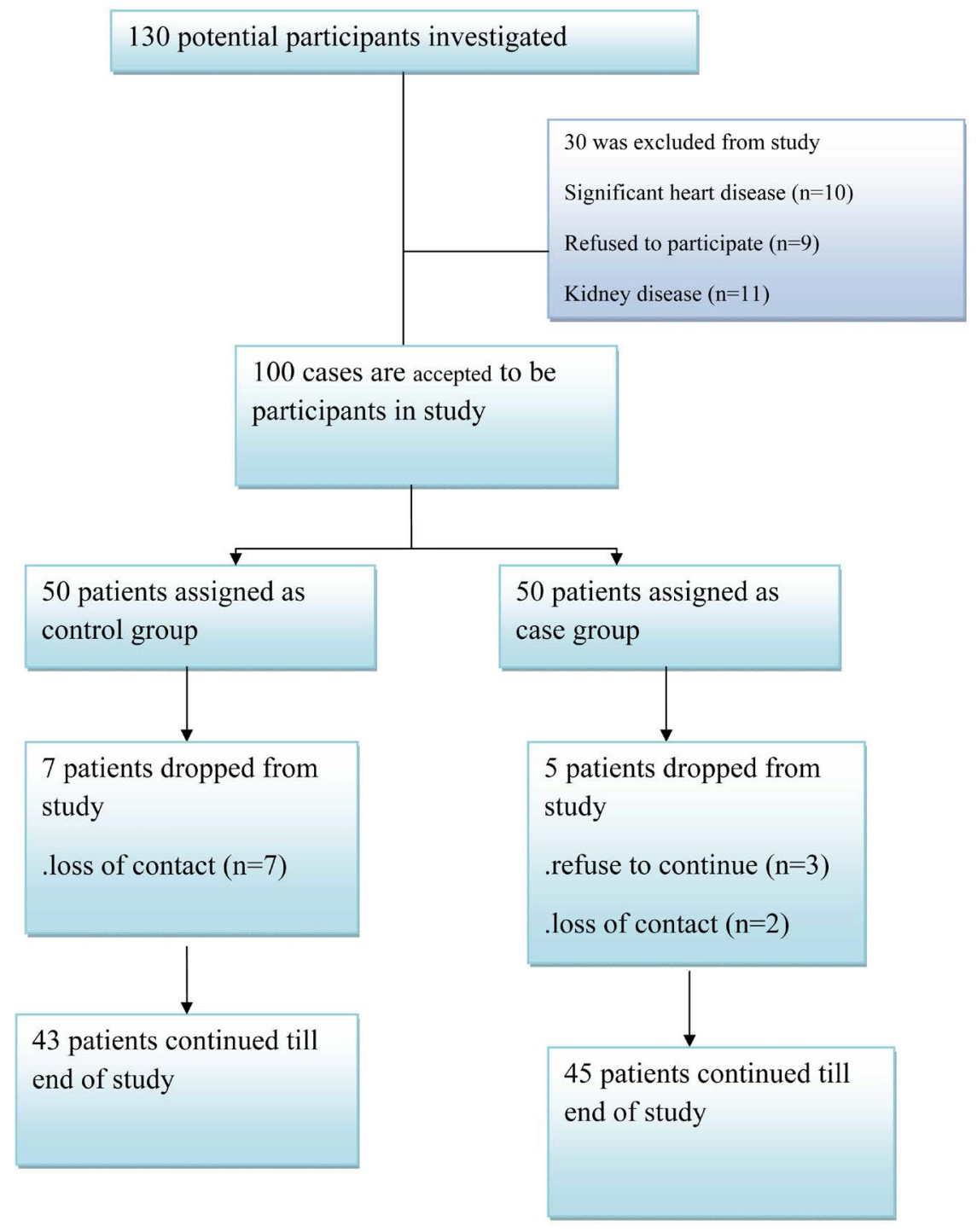

Figure 2. Shows the diagram of sample and sample procedure during study period. Note: $\mathrm{n}=$ number of the patient. 


\subsection{Inclusion Criteria}

Any adult patient diagnosed as hypertensive male or female without complications, who respect and able to apply the plan and mentally sound is eligible to be included in this study.

\subsection{Exclusion Criteria}

Hypertensive patient child, adult mentally un-cognitive, who have complications and not able to apply the plan will be excluded from the study.

\subsection{Interventions}

Interventions were done as follow: (Measurement of blood pressure) potential participants were asked to refrain from smoking or ingesting caffeine for at least 30 minutes before their appointment time. Measurements were standardized for cuff size, position, environment, and time of day. After 5 minutes of quiet rest, 4 seated BP readings, each 2 minutes apart, were obtained using electronic sphygmomanometer.

The blood pressure was measured at the beginning as baseline date for both cases and control groups then every month for 10 months to compare the result.

The researcher discussed teaching program to be taught to the case group individually, each participant in case group should possess book for teaching program, in teaching program each patient was taught individually about DASH to eat food low in saturated fat, cholesterol, and total fat and emphasis was placed on fruits, vegetables, and fat-free or low-fat milk and milk products.

$\checkmark$ The teaching book about dietary approach to stop hypertension.

$\checkmark$ Follow up sheets for both case and control groups.

\subsection{Methods of Data Collection}

The data were collected by using two methods: Direct measurement of blood pressure and self-administrated questionnaire.

\section{Self-Administrated Questionnaire}

The questionnaire is designed to assess level of knowledge of patients under study about dietary approach to stop hypertension, life-style of patients, follow-up, strategies follow to maintain blood pressure is acceptable measure, type of diet and exercise.

The data collected by questionnaire for both case and control group to know the baseline information.

The blood pressure was measured at the beginning as baseline date for both case and control group then every month for 10 months to compare the result.

\subsection{Data Analysis}

The researcher was used Statistical Package for the Social Sciences (SPSS) to analyze the results. 


\subsection{Ethical Clearance}

$\checkmark$ Approval from EL Ribat University was obtained.

$\checkmark$ Verbal consent of patients (participants) was obtained.

\section{Result}

The total population under study was 100 patients: 69 were female 35 in intervention group 34 control group and 31 were male 15 intervention group and 16 control group (Table 1 ).

(68\%) of intervention group and (72\%) of control group were in medial age between 31 years to 60 years and (28\%) above 60 years while (4\%) were 30 years and less in intervention group (Table 2).

The most of population included in the study were housewives (32\%) in intervention group and (32\%) in control group and (12\%) were employees in control group and (10\%) employee in intervention group (Table 3 ).

Most of patients under study had pre-hypertension stage which presented (44\%) in case and (46\%) in control group, (30\%) have stage I hypertension in each cases and control while (16\%) were stage II of hypertension in case and (18\%) in control group, (10\%) have $160 / 100 \mathrm{~mm} \cdot \mathrm{Hg}$ in case group and (6\%) have more than $160 / 100 \mathrm{~mm} \cdot \mathrm{Hg}$ in control group (Table 4).

$(52 \%)$ of patients had single antihypertensive medication in intervention

Table 1. Gender of population under study.

\begin{tabular}{ccc}
\hline Gender & Intervention Group & Control Group \\
\hline Male & $15(30 \%)$ & $16(32 \%)$ \\
Female & $35(70 \%)$ & $34(68 \%)$ \\
Total & $50(100 \%)$ & $50(100 \%)$ \\
\hline
\end{tabular}

Table 2. Age of the study population.

\begin{tabular}{ccc}
\hline Age Group & Intervention Group & Control Group \\
\hline Less than 30 Year & $2(4 \%)$ & $0(0 \%)$ \\
$31-60$ Year & $34(68 \%)$ & $36(72 \%)$ \\
More than 60 Year & $14(28 \%)$ & $14(28 \%)$ \\
Total & $50(100 \%)$ & $50(100 \%)$ \\
\hline
\end{tabular}

Table 3. Occupation of study population.

\begin{tabular}{ccc}
\hline Occupation & Intervention Group & Control Group \\
\hline Employee & $5(10 \%)$ & $6(12 \%)$ \\
Labor & $4(8 \%)$ & $6(12 \%)$ \\
Housewife & $16(32 \%)$ & $16(32 \%)$ \\
Others & $25(50 \%)$ & $22(24 \%)$ \\
Total & $50(100 \%)$ & $50(100 \%)$ \\
\hline
\end{tabular}


Table 4. Base line blood pressure of patients under study.

\begin{tabular}{ccc}
\hline Base Line Blood Pressure & Intervention Group & Control Group \\
\hline $120-139 / 80-89 \mathrm{~mm} \cdot \mathrm{hg}$ & $22(44 \%)$ & $23(46 \%)$ \\
$140-159 / 90-99 \mathrm{~mm} \cdot \mathrm{hg}$ & $15(30 \%)$ & $15(30 \%)$ \\
$160 / 100 \mathrm{~mm} \cdot \mathrm{hg}$ & $8(16 \%)$ & $9(18 \%)$ \\
More than $160 / 100 \mathrm{~mm} \cdot \mathrm{hg}$ & $5(10 \%)$ & $3(6 \%)$ \\
Total & $50(100 \%)$ & $50(100 \%)$ \\
\hline
\end{tabular}

group and (46\%) in control group, (32\%) of patients have two antihypertensive medications in control, (28\%) had two antihypertensives in intervention group and (20\%) were on three antihypertensive drugs in case and control (Table 5).

The mean value of systolic blood pressure at basic measure in cases $(n=44)$ was $144.1 \pm 12.29$ while in control group $(n=44)$ was $140.3 \pm 12.1$, which was not significantly different $(\mathrm{p}=0.159>0.05)$ (Table 6).

The mean value of systolic blood pressure at first month measure in cases (n44) was $142.0 \pm 12.0$ while in control group $(\mathrm{n}=44)$ was $142.1 \pm 11.2$, which was not significantly different $(\mathrm{p}=0.985>0.05)$ (Table 6).

The mean value of systolic blood pressure at second month measure in cases $(\mathrm{n}=44)$ was $140.2 \pm 9.0$ while in control group $(\mathrm{n}=44)$ was $141.5 \pm 11.5$, which was not significantly different $(\mathrm{p}=0.564>0.05)$ (Table 6$)$.

The mean value of systolic blood pressure at the third month measure in cases $(\mathrm{n}=44)$ was $138.4 \pm 11.1$ while in control group $(\mathrm{n}=44)$ was $142.3 \pm 11.4$, which was not significantly different $(\mathrm{p}=0.109>0.05)$ (Table 6).

The mean value of systolic blood pressure at the fourth month measure in cases $(n=44)$ was $137.5 \pm 11.5$ while in control group $(n=44)$ was $142.8 \pm 11.2$, which was significantly different (lower in cases and higher in control) $(\mathrm{p}=$ $0.032<0.05)$ (Table 6).

The mean value of systolic blood pressure at the fifth month measure in cases $(\mathrm{n}=44)$ was $137.4 \pm 11.3$ while in control group $(\mathrm{n}=44)$ was $142.3 \pm 10.9$, which was significantly different (lower in cases and higher in control) $(\mathrm{p}=$ $0.045<0.05)$ (Table 6).

The mean value of systolic blood pressure at the sixth month measure in cases $(\mathrm{n}=44)$ was $136.8 \pm 10.7$ while in control group $(\mathrm{n}=44)$ was $142.4 \pm 11.1$, which was significantly different (lower in cases and higher in control) $(\mathrm{p}=$ $0.019<0.05)$ (Table 6).

The mean value of systolic blood pressure at the seventh month measure in cases $(\mathrm{n}=44)$ was $136.2 \pm 10.6$ while in control group $(\mathrm{n}=44)$ was $142.7 \pm 10.4$, which was significantly different (lower in cases and higher in control) $(\mathrm{p}=$ $0.005<0.05)$ (Table 6).

The mean value of systolic blood pressure at the eighth month measure in cases $(n=44)$ was $136.2 \pm 10.4$ while in control group $(n=44)$ was $143.2 \pm 10.2$, which was significantly different (lower in cases and higher in control) $(\mathrm{p}=$ $0.032<0.002)$ (Table 6). 
Table 5. Number of antihypertensive medications used by patient.

\begin{tabular}{ccc}
\hline Anti HTN Drugs & Intervention Group & Control Group \\
\hline Single Antihypertension & $26(52 \%)$ & $23(46 \%)$ \\
Two Antihypertension & $14(28 \%)$ & $16(32 \%)$ \\
Three Antihypertension & $10(20 \%)$ & $11(22 \%)$ \\
Total & $50(100 \%)$ & $50(100 \%)$ \\
\hline
\end{tabular}

Table 6. The differences in systolic pressure between cases (intervention group) and control group $(\mathrm{n}=88)$.

\begin{tabular}{ccccccccccc}
\hline \multirow{2}{*}{ Months } & \multicolumn{2}{c}{ Cases } & \multicolumn{2}{c}{ Control } & \multicolumn{7}{c}{ CI 95\% } & \multirow{2}{*}{ t } & DF & p \\
\cline { 2 - 7 } & Mean & SD & Mean & SD & SE & Lower & Upper & & & \\
\hline Basic BP & 144.1 & 12.9 & 140.3 & 12.1 & 2.7 & -1.5 & 9.1 & 1.4 & 86 & 0.159 \\
First Month & 142.0 & 12.0 & 142.1 & 11.2 & 2.5 & -5.0 & 4.9 & 0.0 & 86 & 0.985 \\
Second Month & 140.2 & 9.0 & 141.5 & 11.5 & 2.2 & -5.6 & 3.1 & -0.6 & 86 & 0.564 \\
Third Month & 138.4 & 11.1 & 142.3 & 11.4 & 2.4 & -8.7 & 0.9 & -1.6 & 86 & 0.109 \\
Forth Month & 137.5 & 11.5 & 142.8 & 11.2 & 2.4 & -10.1 & -0.5 & -2.2 & 86 & 0.032 \\
Fifth Month & 137.4 & 11.3 & 142.3 & 10.9 & 2.4 & -9.5 & -0.1 & -2.0 & 86 & 0.045 \\
Sixth Month & 136.8 & 10.7 & 142.4 & 11.1 & 2.3 & -10.2 & -0.9 & -2.4 & 86 & 0.019 \\
Seventh Month & 136.2 & 10.6 & 142.7 & 10.4 & 2.2 & -10.9 & -2.0 & -2.9 & 86 & 0.005 \\
Eighth Month & 136.2 & 10.4 & 143.2 & 10.2 & 2.2 & -11.4 & -2.7 & -3.2 & 86 & 0.002 \\
Ninth Month & 135.5 & 10.2 & 143.6 & 10.1 & 2.2 & -12.4 & -3.8 & -3.8 & 86 & 0.000 \\
Tenth Month & 135.0 & 9.6 & 143.3 & 9.2 & 2.0 & -12.4 & -4.4 & -4.2 & 86 & 0.000 \\
\hline
\end{tabular}

The mean value of systolic blood pressure at the ninth month measure in cases $(n=44)$ was $135.5 \pm 10.2$ while in control group $(n=44)$ was $143.6 \pm 10.1$, which was significantly different (lower in cases and higher in control) $(\mathrm{p}=$ $0.000<0.05)$ (Table 6).

The mean value of systolic blood pressure at the tenth month measure in cases $(\mathrm{n}=44)$ was $135.0 \pm 9.6$ while in control group $(\mathrm{n}=44)$ was $143.3 \pm 9.2$, which was significantly different (lower in cases and higher in control) $(\mathrm{p}=0.000<$ 0.05) (Table 6).

The mean value of diastolic blood pressure at basic measure in cases (n44) was $92.1 \pm 6.0$ while in control group $(n=44)$ was $85 \pm 1.6$, which was significantly different (higher in cases and lower in control) $(\mathrm{p}=0.001<0.05)$ (Table 7).

The mean value of diastolic blood pressure at first month measure in cases (n44) was $90.4 \pm 8.2$ while in control group $(n=44)$ was $85.9 \pm 9.3$, which was significantly different (higher in cases and lower in control) $(\mathrm{p}=0.018<0.05)$ (Table 7).

The mean value of diastolic blood pressure at second month measure in cases $(\mathrm{n}=44)$ was $86.6 \pm 7.0$ while in control group $(\mathrm{n}=44)$ was $88.8 \pm 7.1$, which was not significantly different $(\mathrm{p}=0.153>0.05)$ (Table 7$)$.

The mean value of diastolic blood pressure at the third month measure in 
Table 7. The differences in diastolic pressure between cases (intervention group) and control group $(\mathrm{n}=88)$.

\begin{tabular}{|c|c|c|c|c|c|c|c|c|c|c|}
\hline \multirow{2}{*}{ Months } & \multicolumn{2}{|c|}{ Cases } & \multicolumn{2}{|c|}{ Control } & \multicolumn{3}{|c|}{ CI $95 \%$} & \multirow{2}{*}{$t$} & \multirow{2}{*}{ DF } & \multirow{2}{*}{$\mathrm{p}$} \\
\hline & Mean & $\mathrm{SD}$ & Mean & SD & SE & Lower & Upper & & & \\
\hline Basic BP & 92.1 & 6.0 & 85.0 & 8.5 & 1.6 & 4.0 & 10.2 & 4.5 & 86 & 0.001 \\
\hline First Month & 90.4 & 8.2 & 85.9 & 9.3 & 1.9 & 0.8 & 8.2 & 2.4 & 86 & 0.018 \\
\hline Second Month & 86.6 & 7.0 & 88.8 & 7.1 & 1.5 & -5.1 & 0.8 & -1.4 & 86 & 0.152 \\
\hline Third Month & 87.9 & 5.6 & 88.2 & 8.0 & 1.5 & -3.3 & 2.6 & -0.2 & 86 & 0.817 \\
\hline Forth Month & 88.1 & 5.7 & 90.2 & 6.8 & 1.3 & -4.7 & 0.6 & -1.5 & 86 & 0.134 \\
\hline Fifth Month & 87.7 & 5.3 & 90.0 & 6.2 & 1.2 & -4.7 & 0.1 & -1.9 & 86 & 0.064 \\
\hline Sixth Month & 87.5 & 5.4 & 90.2 & 6.0 & 1.2 & -5.1 & -0.2 & -2.2 & 86 & 0.032 \\
\hline Seventh Month & 86.8 & 5.2 & 90.4 & 6.1 & 1.2 & -5.9 & -1.1 & -2.9 & 86 & 0.004 \\
\hline Eighth Month & 86.4 & 5.1 & 90.9 & 5.1 & 1.1 & -6.6 & -2.3 & -4.1 & 86 & 0.001 \\
\hline Ninth Month & 86.5 & 5.2 & 91.2 & 5.7 & 1.2 & -7.0 & -2.3 & -4.0 & 86 & 0.001 \\
\hline Tenth Month & 86.5 & 5.2 & 91.2 & 5.5 & 1.1 & -6.9 & -2.4 & -4.0 & 86 & 0.001 \\
\hline
\end{tabular}

cases $(\mathrm{n}=44)$ was $87.9 \pm 5.6$ while in control group $(\mathrm{n}=44)$ was $88.2 \pm 8.0$, which was not significantly different $(\mathrm{p}=0.817>0.05)$ (Table 7).

The mean value of diastolic blood pressure at the fourth month measure in cases $(n=44)$ was $88.1 \pm 5.7$ while in control group $(n=44)$ was $90.2 \pm 6.8$, which was not significantly different $(\mathrm{p}=0.134>0.05)$ (Table 7).

The mean value of diastolic blood pressure at the fifth month measure in cases $(\mathrm{n}=44)$ was $87.7 \pm 5.3$ while in control group $(\mathrm{n}=44)$ was $90.0 \pm 6.2$, which was not significantly different $(\mathrm{p}=0.064>0.05)$ (Table 7).

The mean value of diastolic blood pressure at the sixth month measure in cases $(n=44)$ was $87.5 \pm 5.4$ while in control group $(n=44)$ was $90.2 \pm 6.0$, which was significantly different (lower in cases and higher in control) $(\mathrm{p}=0.032<$ 0.05) (Table 7).

The mean value of diastolic blood pressure at the seventh month measure in cases $(n=44)$ was $86.8 \pm 5.2$ while in control group $(n=44)$ was $90.4 \pm 6.1$, which was significantly different (lower in cases and higher in control) ( $\mathrm{p}=$ $0.004<0.05)$ (Table 7).

The mean value of diastolic blood pressure at the eighth month measure in cases $(n=44)$ was $86.4 \pm 5.1$ while in control group $(n=44)$ was $90.9 \pm 5.1$, which was significantly different (lower in cases and higher in control) $(\mathrm{p}=0.001<$ 0.005) (Table 7).

The mean value of diastolic blood pressure at the ninth month measure in cases $(n=44)$ was $86.5 \pm 5.2$ while in control group $(n=44)$ was $91.2 \pm 5.7$, which was significantly different (lower in cases and higher in control) $(\mathrm{p}=0.001<$ 0.05) (Table 7).

The mean value of diastolic blood pressure at the tenth month measure in cases $(n=44)$ was $86.5 \pm 9.6$ while in control group $(n=44)$ was $91.2 \pm 5.5$, 
which was significantly different (lower in cases and higher in control) $(\mathrm{p}=$ $0.001<0.05)$ (Table 7).

\section{Discussions}

This study was done on hypertensive patients to assess the effectiveness of (DASH) approach through reducing high blood pressures.

The results of this study show that (44\%) of intervention group and (46\%) of control group had pre-hypertension, (30\%) of each control and intervention group had first stage hypertension and (10\%) had blood pressure more than $160 / 100 \mathrm{mmHg}$ in intervention group; all of them were on antihypertensive drug (52\%) had single antihypertensive in intervention group, (28\%) two antihypertensive drugs in intervention group and (20\%) three antihypertensive drugs in intervention group while in control group (46\%), (32\%) and (22\%) respectively (Table 4 and Table 5).

This study shows the mean value of systolic blood pressure at basic measurement in cases $(\mathrm{n}=44)$ was $144.1 \pm 12.29$ while in control group $(\mathrm{n}=44)$ was $140.3 \pm 12.1$, which was not significantly different $(\mathrm{p}=0.159>0.05)$ (Table 6).

The significant changes occurred in the mean value of systolic blood pressure at the fourth month measure in cases $(\mathrm{n}=44)$ was $137.5 \pm 11.5$ while in control group $(\mathrm{n}=44)$ was $142.8 \pm 11.2$, which was significantly different (lower in cases and higher in control) $(\mathrm{p}=0.032<0.05)$ (Table 6).

The changes became more significant in months after 4 th month as the mean value of systolic blood pressure at the 10th month measure in cases $(n=44)$ was $135.0 \pm 9.6$ while in control group $(\mathrm{n}=44)$ was $143.3 \pm 9.2$, which was significantly different (lower in cases and higher in control) $(\mathrm{p}=0.000<0.05)$ (Table $6)$.

DASH eating plan had the greatest effect in high blood pressure and blood pressure reduction came fast within 2 weeks of starting plan [18].

In 6th month trial period blood pressure occur $12 \mathrm{mmHg}$ systolic in men and $11 \mathrm{~mm} \cdot \mathrm{Hg}$ in women while diastolic decreased by $6 \mathrm{~mm} \cdot \mathrm{Hg}$ in men and 7 $\mathrm{mm} \cdot \mathrm{Hg}$ in women [19].

More than 4th week low sodium intake is effective in reducing blood pressure [20].

Lowering sodium intake whatever eating plan can contribute in reduction of blood pressure [18].

The results of this study are in line with that study done on United State to compare diet containing low sodium and other with traditional eating of United State of America DASH eating plan, the result of that was reducing dietary sodium lowered blood pressure for both eating plans. The greatest blood pressure reductions were for the DASH eating plan at the sodium intake of 1500 milligrams per day. Those with high blood pressure showed the greatest reductions, importance to lowering sodium intake whatever your eating plan [18].

In the primary screening the mean value of basic diastolic blood pressure 
measure in cases $(n=44)$ was $92.1 \pm 6.0$ while in control group $(n=44)$ was 85 \pm 1.6 , which was significantly different (higher in cases and lower in control) ( $\mathrm{p}$ $=0.001<0.05)($ Table 7$)$.

The changes became significant at the 6th month the mean value of diastolic blood pressure at the sixth month measure in cases $(n=44)$ was $87.5 \pm 5.4$ while in control group $(\mathrm{n}=44)$ was $90.2 \pm 6.0$, which was significantly different (lower in cases and higher in control) $(\mathrm{p}=0.032<0.05)$ (Table 7$)$.

The changes became more significant after 6 th month the mean value of diastolic blood pressure at the 10th month measure in cases $(n=44)$ was $86.5 \pm 9.6$ while in control group $(\mathrm{n}=44)$ was $91.2 \pm 5.5$, which was significantly different (lower in cases and higher in control) $(\mathrm{p}=0.001<0.05)$ (Table 7).

This result going with that done by (Whitt-Glover MC) in North Carolina which shows no significant changes occurred in blood pressure after 12th week of application of the DASH approach [21].

The results of this study were in line with that study done by (Blumenthal JA, Babyak MA) in the United States of America to assess the DASH diet alone and in combination with exercise and weight loss which shows that the blood pressure was reduced by 16.1/9.9 $\mathrm{mm} \cdot \mathrm{Hg}$ (DASH plus weight management); 11.2/7.5 $\mathrm{mm} \cdot \mathrm{Hg}$ (DASH alone); and 3.4/3.8 mm.Hg (usual diet controls) $(\mathrm{p}<0.001)$ [22].

The important findings show significant changes $(\mathrm{p}=0.03)$ occurred in systolic blood pressure after 4th month; while in diastolic blood pressure significant changes $(p=0.032)$ occurred after 6th month and became more significant in next months.

Some of studies done were different with this results in the time of blood pressure starting to decline, like study done by national institutes of health and national heart, lung and blood institute department of health and human services in U.S. (United States) participants who followed both the plan that included more fruits and vegetables and the DASH eating plan had reduced blood pressure. But the DASH eating plan had the greatest effect, especially for those with high blood pressure. Furthermore, the blood pressure reductions came fast within 2 weeks of starting the plan [18].

Based on the research findings, the DASH diet could be adopted as part of current national recommendations for the prevention and treatment of high BP.

The first line of prevention and management of hypertension is life-style change include dietary changes, physical exercise and weight reduction; potential affect is similar to single antihypertensive medication [20].

\section{Conclusion}

DASH eating plan is a diet rich in fruits, vegetables, and low-fat dairy foods, reduced saturated and total fat; application of this program leads to significant substantial changes, it is clear that both systolic and diastolic blood pressure of the cases (intervention group) decreased compared with control group, with no significant differences at basic measure, then significantly different by 4 th month 
in systolic BP and by 6th month in diastolic BP (lower in cases and higher in control).

\section{Recommendations}

According to the results of case control study the researcher recommends the following:

1) Education for health care workers, social workers and nutritionist about dietary approach to stop hypertension (DASH) should be rendered.

2) DASH is recommended to be introduced in curriculum of health, nursing and nutritional sciences.

3) Extensive education should be extended to the community on DASH especially to hypertensive patients.

4) It is necessary to apply a nutritional approach to all hypertensive patients because it could minimize both the healthcare workload and the high cost for therapy in clinical area.

5) Further studies should be conducted in a large group of patients to evaluate the possibility of clinical application to other chronic diseases like heart disease is recommended.

6) Government should support poor hypertensive patients to follow DASH and to have antihypertensive drugs in their hands.

\section{Conflicts of Interest}

The author declares no conflicts of interest regarding the publication of this paper.

\section{References}

[1] National Institutes of Health and National Heart, Lung, and Blood Institute (2006) U.S. Department of Health and Human Services NIH Publication No. 06-4082. http://www.nhlbi.nih.gov/health/public/heart/hbp/dash/new dash.pdf

[2] WHO (2008). http://www.who.int/gho/ncd/risk factors/blood pressure prevalence text/en

[3] Kearney, P.M., Whelton, M., Reynolds, K., Muntner, P. and Whelton, P.K. (2005) Global Burden of Hypertension: Analysis of Worldwide Data. The Lancet, 365, 217-223. https://doi.org/10.1016/S0140-6736(05)17741-1

[4] Kearney, P.M., Whelton, M., Reynolds, K., Whelton, P.K. and He, J. (2004) Worldwide Prevalence of Hypertension: A Systematic Review. Journal of Hypertension, 22, 11-19. https://doi.org/10.1097/00004872-200401000-00003

[5] Giuseppe, M., et al. (2013) ESH/ESC Guidelines for the Management of Arterial Hypertension: The Task Force for the Management of Arterial Hypertension of the European Society of Hypertension (ESH) and of the European Society of Cardiology (ESC). European Heart Journal, 34, 2159-2219.

https://doi.org/10.1093/eurheartj/eht151

[6] Burt, V.L., Whelton, P., Roccella, E.J., et al. (1995) Prevalence of Hypertension in the US Adult Population. Results from the Third National Health and Nutrition Examination Survey, 1988-1991. Hypertension, 25, 305-313. 


\section{https://doi.org/10.1161/01.HYP.25.3.305}

[7] Ostchega, Y., Dillon, C.F., Hughes, J.P., Carroll, M. and Yoon, S. (2007) Trends in Hypertension Prevalence, Awareness, Treatment, and Control in Older U.S. Adults: Data from the National Health and Nutrition Examination Survey 1988 to 2004. Journal of the American Geriatrics Society, 55, 1056-1065. https://doi.org/10.1111/j.1532-5415.2007.01215.x

[8] Lloyd-Jones, D., Adams, R.J., Brown, T.M., et al. (2010) Heart Disease and Stroke Statistics-2010 Update: A Report from the American Heart Association. Circulation, 121, e46-e215.

[9] Mittal, B.V. and Singh, A.K. (2010) Hypertension in the Developing World: Challenges and Opportunities. American Journal of Kidney Diseases, 55, 590-598. https://doi.org/10.1053/j.ajkd.2009.06.044

[10] Elbagir, M. and Ahmed, K. (2012) Blood Pressure in a Multiracial Urban Sudanese Community. Journal of Human Hypertension, 4, 621-624.

[11] Suliman, A. (2011) The State of Heart Disease in Sudan. Cardiovascular Journal of Africa, 22, 191-196. https://doi.org/10.5830/CVJA-2010-054

[12] Addo, J., Smeeth, L. and Leon, D. (2007) Hypertension in Sub-Saharan Africa: A Systematic Review. Hypertension, 50, 1012-1018. https://doi.org/10.1161/HYPERTENSIONAHA.107.093336

[13] Elsevier, A.G., Hussain, A.A., Suleiman, I.S. and Hamid, Z.A. (2000) Drug Compliance among Hypertensive Patients in Kassala, Eastern Sudan. Eastern Mediterranean Health Journal, 6, 100-106.

[14] Uma, J.N. (2012) Old People at Risk of Chronic Non-Communicable Diseases: WHO. Sudan Tribune.

[15] WHO (2014) Word Health Ranking of Hypertension. http://www.worldlifeexpectancy.com/sudan-hypertension

[16] National Institute of Health, National Heart, Lung and Blood Institute (2006) Your Guide to Lowering Your Blood Pressure with DASH. 6. http://www.nhlbi.nih.gov/health/public/heart/hbp/dash/new dash.pdf

[17] Siham, A., Asma, A., Taha, A. and Ahmed, H.A. (2014) Hypertension among Rural Population in Four States Sudan. Global Journal of Health Science, 6, 206-212. https://doi.org/10.5539/gjhs.v6n3p206

[18] National Institutes of Health, National Heart, Lung, and Blood Institute (1998) NIH Publication No. 06-4082.

[19] National Heart Lung and Blood Institute (2006) Your Guide to Lowering Your Blood Pressure with DASH. http://www.nhlbi.nih.gov/health/public/heart/hbp/dash/new dash.pdf

[20] Go, A.S., Bauman, M., King, S.M., et al. (2013) An Effective Approach to High Blood Pressure Control: A Science Advisory from the American Heart Association, the American College of Cardiology, and the Centers for Disease Control and Prevention. Journal of the American College of Cardiology, 63, 1230-1238. https://doi.org/10.1161/HYP.0000000000000003

[21] Whitt-Glover, M.C., Hunter, J.C., Foy, C.G., Quandt, S.A., Vitolins, M.Z., Leng, I., et al. (2013) Translating the Dietary Approaches to Stop Hypertension (DASH) Diet for Use in Underresourced, Urban African American Communities 2010. Preventing Chronic Disease, 10, Article ID: 120088. https://doi.org/10.5888/pcd10.120088

[22] Blumenthal, J.A., Babyak, M.A., Hinderliter, A., Watkins, L.L., Craighead, L., Lin, P.H., Caccia, C., Johnson, J., Waugh, R. and Sherwood, A. (2010) Effects of the 
DASH Diet Alone and in Combination with Exercise and Weight Loss on Blood Pressure and Cardiovascular Biomarkers in Men and Women with High Blood Pressure: The ENCORE Study. The Archives of Internal Medicine, 170, 126-135. 
Annex 1. Cases (Intervention Group) Follow up Sheet

\begin{tabular}{|c|c|c|c|c|c|c|c|c|c|c|c|c|}
\hline Case name & Basic BP & $\begin{array}{c}\text { First } \\
\text { month }\end{array}$ & $\begin{array}{l}\text { Second } \\
\text { month }\end{array}$ & $\begin{array}{l}\text { Third } \\
\text { month }\end{array}$ & $\begin{array}{l}\text { Four } \\
\text { month }\end{array}$ & $\begin{array}{c}\text { Five } \\
\text { month }\end{array}$ & $\begin{array}{c}\text { Six } \\
\text { month }\end{array}$ & $\begin{array}{l}\text { Seven } \\
\text { month }\end{array}$ & $\begin{array}{l}\text { Eight } \\
\text { month }\end{array}$ & $\begin{array}{l}\text { Nine } \\
\text { month }\end{array}$ & $\begin{array}{c}\text { Ten } \\
\text { month }\end{array}$ & Notes \\
\hline 1 & $129 / 92$ & $126 / 84$ & $126 / 87$ & $114 / 82$ & $120 / 86$ & $126 / 85$ & $128 / 88$ & $129 / 86$ & $126 / 85$ & $120 / 87$ & $126 / 87$ & \\
\hline 2 & $130 / 100$ & $129 / 97$ & $130 / 87$ & $130 / 92$ & $130 / 97$ & $130 / 97$ & $130 / 97$ & $130 / 87$ & $130 / 87$ & $130 / 92$ & $130 / 92$ & \\
\hline 3 & $130 / 88$ & $130 / 88$ & $130 / 82$ & $130 / 88$ & $130 / 88$ & $130 / 88$ & $130 / 82$ & $130 / 82$ & $130 / 82$ & $130 / 82$ & $130 / 82$ & \\
\hline 4 & $160 / 100$ & $156 / 125$ & $150 / 95$ & $160 / 100$ & $160 / 100$ & $160 / 100$ & $160 / 100$ & $156 / 95$ & $150 / 95$ & $156 / 95$ & $126 / 95$ & \\
\hline 5 & $130 / 95$ & $130 / 95$ & $136 / 76$ & $130 / 90$ & $130 / 90$ & $130 / 90$ & $128 / 88$ & $128 / 88$ & $128 / 88$ & $130 / 88$ & $130 / 87$ & \\
\hline 6 & $110 / 90$ & $111 / 80$ & $137 / 82$ & $136 / 84$ & $116 / 82$ & $137 / 82$ & $136 / 84$ & $137 / 82$ & $137 / 82$ & $130 / 82$ & $130 / 82$ & \\
\hline 7 & $130 / 90$ & $130 / 87$ & $130 / 87$ & $130 / 87$ & $130 / 86$ & $126 / 86$ & $120 / 86$ & $126 / 86$ & $126 / 86$ & $125 / 85$ & $125 / 85$ & \\
\hline 8 & $136 / 97$ & $136 / 95$ & $157 / 90$ & $129 / 89$ & $130 / 90$ & $130 / 90$ & $130 / 90$ & $127 / 89$ & $130 / 89$ & $130 / 89$ & $130 / 89$ & \\
\hline 9 & $135 / 87$ & $135 / 85$ & $130 / 80$ & $135 / 87$ & $135 / 85$ & $135 / 85$ & $135 / 85$ & $130 / 80$ & $130 / 80$ & $130 / 80$ & $130 / 80$ & \\
\hline 10 & $139 / 90$ & $139 / 87$ & $135 / 87$ & & & & & & & & & dropped \\
\hline 11 & $160 / 100$ & $160 / 95$ & $160 / 95$ & $155 / 95$ & $155 / 95$ & $150 / 95$ & & & & & & dropped \\
\hline 12 & $180 / 110$ & $180 / 110$ & $140 / 80$ & $170 / 105$ & $170 / 105$ & $170 / 100$ & $170 / 100$ & $175 / 100$ & $175 / 100$ & $165 / 100$ & $165 / 100$ & \\
\hline 13 & $153 / 81$ & $150 / 80$ & $150 / 80$ & $150 / 80$ & $150 / 80$ & $150 / 80$ & $150 / 80$ & $145 / 80$ & $145 / 80$ & $145 / 80$ & $145 / 80$ & \\
\hline 14 & $160 / 85$ & $140 / 80$ & $140 / 80$ & $135 / 80$ & $130 / 80$ & $130 / 80$ & $130 / 80$ & $128 / 79$ & $130 / 80$ & $130 / 80$ & $130 / 80$ & \\
\hline 15 & $160 / 100$ & $150 / 100$ & $150 / 95$ & $150 / 95$ & $145 / 95$ & $150 / 95$ & $150 / 95$ & $155 / 95$ & $155 / 95$ & $155 / 95$ & $155 / 95$ & \\
\hline 16 & $140 / 90$ & $140 / 90$ & $140 / 88$ & $135 / 87$ & $135 / 87$ & $135 / 88$ & $135 / 88$ & $135 / 88$ & $135 / 88$ & $130 / 86$ & $136 / 86$ & \\
\hline 17 & $160 / 90$ & $165 / 87$ & $160 / 87$ & $160 / 87$ & $165 / 87$ & $165 / 87$ & $160 / 86$ & $155 / 86$ & $155 / 86$ & $155 / 86$ & $155 / 86$ & \\
\hline 18 & $130 / 87$ & $130 / 86$ & $130 / 87$ & $130 / 87$ & $130 / 87$ & $130 / 85$ & $130 / 85$ & $130 / 85$ & $125 / 80$ & $125 / 80$ & $125 / 80$ & \\
\hline 19 & $154 / 90$ & $154 / 83$ & $154 / 83$ & $154 / 83$ & $150 / 82$ & $150 / 82$ & $145 / 82$ & $145 / 82$ & $145 / 82$ & $145 / 82$ & $145 / 82$ & \\
\hline 20 & $140 / 95$ & $140 / 90$ & $140 / 90$ & $135 / 90$ & $130 / 90$ & $130 / 90$ & $130 / 90$ & $130 / 90$ & $130 / 90$ & $125 / 90$ & $125 / 90$ & \\
\hline 21 & $170 / 100$ & $170 / 90$ & $160 / 90$ & $160 / 95$ & $160 / 95$ & $155 / 90$ & $155 / 90$ & $155 / 90$ & $150 / 90$ & $150 / 90$ & $150 / 90$ & \\
\hline 22 & $140 / 90$ & $140 / 90$ & $130 / 90$ & $130 / 80$ & $130 / 85$ & $130 / 85$ & $135 / 85$ & $130 / 80$ & $130 / 80$ & $130 / 80$ & $130 / 80$ & \\
\hline 23 & $160 / 90$ & $160 / 90$ & $155 / 85$ & $155 / 85$ & $155 / 85$ & $155 / 85$ & $150 / 80$ & $150 / 80$ & $150 / 80$ & $150 / 80$ & $150 / 80$ & \\
\hline 24 & $140 / 80$ & $140 / 80$ & $135 / 80$ & $130 / 80$ & $130 / 80$ & $130 / 80$ & $130 / 80$ & $130 / 80$ & $130 / 80$ & $130 / 80$ & $130 / 80$ & \\
\hline 25 & $131 / 84$ & $131 / 84$ & $130 / 85$ & $130 / 80$ & $120 / 80$ & $120 / 80$ & $120 / 80$ & $120 / 80$ & $120 / 80$ & $125 / 80$ & $120 / 80$ & \\
\hline 26 & $150 / 95$ & $150 / 95$ & $145 / 95$ & $145 / 90$ & $145 / 90$ & $145 / 90$ & $140 / 90$ & $140 / 90$ & $140 / 90$ & $140 / 90$ & $140 / 90$ & \\
\hline 27 & $163 / 96$ & $160 / 95$ & $155 / 90$ & $155 / 90$ & $155 / 90$ & $155 / 90$ & $150 / 88$ & $150 / 88$ & $150 / 88$ & $150 / 88$ & $150 / 88$ & \\
\hline 28 & $150 / 100$ & $145 / 95$ & $145 / 95$ & $145 / 95$ & $140 / 95$ & $140 / 95$ & $135 / 95$ & $135 / 95$ & $135 / 95$ & $130 / 90$ & $130 / 90$ & \\
\hline 29 & $140 / 90$ & $140 / 90$ & $135 / 88$ & $135 / 88$ & $138 / 88$ & $130 / 87$ & $130 / 88$ & $130 / 88$ & $130 / 88$ & $130 / 85$ & $130 / 85$ & \\
\hline 30 & $130 / 86$ & $136 / 86$ & $130 / 85$ & $125 / 85$ & $125 / 85$ & $125 / 85$ & $125 / 85$ & $125 / 85$ & $125 / 85$ & $125 / 85$ & $125 / 85$ & \\
\hline 31 & $140 / 90$ & $140 / 90$ & $140 / 88$ & $135 / 88$ & $135 / 88$ & $130 / 85$ & $130 / 85$ & $130 / 85$ & $130 / 85$ & $130 / 85$ & $130 / 85$ & \\
\hline 32 & $130 / 85$ & $130 / 80$ & $125 / 80$ & $125 / 80$ & $130 / 80$ & $125 / 80$ & $125 / 80$ & $125 / 80$ & $125 / 80$ & $125 / 80$ & $125 / 80$ & \\
\hline 33 & $150 / 95$ & $150 / 90$ & $140 / 90$ & $140 / 90$ & $140 / 90$ & $140 / 90$ & $140 / 90$ & $140 / 90$ & $135 / 88$ & $135 / 88$ & $135 / 88$ & \\
\hline 34 & $140 / 90$ & $135 / 88$ & $135 / 88$ & $130 / 85$ & $130 / 85$ & $130 / 85$ & $130 / 85$ & $130 / 85$ & $130 / 85$ & $130 / 85$ & $130 / 85$ & \\
\hline 35 & $140 / 88$ & $135 / 87$ & $135 / 87$ & $130 / 85$ & $130 / 85$ & $130 / 85$ & $130 / 85$ & $130 / 85$ & $130 / 85$ & $130 / 85$ & $130 / 85$ & \\
\hline 36 & $150 / 90$ & $140 / 85$ & $140 / 85$ & $140 / 85$ & $140 / 85$ & $140 / 85$ & $140 / 85$ & $140 / 85$ & $140 / 84$ & $140 / 84$ & $140 / 84$ & \\
\hline
\end{tabular}


Continued

\begin{tabular}{|c|c|c|c|c|c|c|c|c|c|c|c|c|}
\hline 37 & $150 / 90$ & $140 / 85$ & $140 / 85$ & $140 / 85$ & $140 / 85$ & $140 / 85$ & $140 / 85$ & $140 / 85$ & $140 / 84$ & $140 / 84$ & $140 / 84$ & \\
\hline 38 & $150 / 100$ & $145 / 95$ & $140 / 95$ & $140 / 95$ & $140 / 95$ & $140 / 95$ & $140 / 95$ & $140 / 95$ & $140 / 95$ & $140 / 95$ & $140 / 95$ & \\
\hline 39 & $150 / 100$ & $145 / 95$ & $140 / 95$ & $140 / 95$ & $140 / 95$ & $140 / 95$ & $140 / 95$ & $140 / 95$ & $140 / 85$ & $140 / 95$ & $140 / 95$ & \\
\hline 40 & $160 / 110$ & $150 / 110$ & 150 & 100 & & & & & & & & dropped \\
\hline 41 & $160 / 100$ & $155 / 100$ & $150 / 97$ & & & & & & & & & dropped \\
\hline 42 & $150 / 90$ & $145 / 88$ & $145 / 88$ & $140 / 88$ & $140 / 88$ & $140 / 88$ & $140 / 88$ & $140 / 88$ & $140 / 88$ & $140 / 88$ & $140 / 88$ & \\
\hline 43 & $130 / 88$ & $130 / 85$ & $130 / 85$ & $130 / 85$ & $128 / 85$ & $128 / 85$ & $128 / 85$ & $130 / 85$ & $130 / 85$ & $130 / 85$ & $130 / 85$ & \\
\hline 44 & $140 / 90$ & $140 / 90$ & $140 / 85$ & $130 / 85$ & $130 / 85$ & $130 / 85$ & $130 / 85$ & $130 / 85$ & $130 / 85$ & $130 / 85$ & $130 / 85$ & \\
\hline 45 & $130 / 88$ & $130 / 88$ & $130 / 85$ & $130 / 85$ & $130 / 85$ & $130 / 85$ & $130 / 85$ & $130 / 85$ & $130 / 85$ & $130 / 85$ & $130 / 85$ & \\
\hline 46 & $150 / 88$ & $150 / 88$ & $140 / 85$ & $140 / 85$ & $140 / 85$ & & & & & & & dropped \\
\hline 47 & $160 / 100$ & $155 / 98$ & $155 / 98$ & $150 / 95$ & $150 / 95$ & $150 / 95$ & $150 / 95$ & $140 / 95$ & $140 / 95$ & $145 / 95$ & $145 / 95$ & \\
\hline 48 & $150 / 96$ & $150 / 95$ & $145 / 90$ & $140 / 90$ & $140 / 90$ & $135 / 88$ & $135 / 88$ & $135 / 88$ & $135 / 88$ & $130 / 88$ & $130 / 88$ & \\
\hline 49 & $150 / 96$ & $150 / 95$ & $145 / 90$ & $140 / 90$ & $140 / 90$ & $135 / 88$ & $135 / 88$ & $135 / 88$ & $140 / 88$ & $140 / 88$ & $140 / 88$ & \\
\hline 50 & $150 / 98$ & $150 / 97$ & $145 / 97$ & $145 / 97$ & $140 / 95$ & $145 / 95$ & $145 / 95$ & $145 / 95$ & $145 / 95$ & $140 / 95$ & $140 / 95$ & \\
\hline
\end{tabular}

Annex 2. Control Follow up Sheet

\begin{tabular}{|c|c|c|c|c|c|c|c|c|c|c|c|c|}
\hline Case name & Basic BP & $\begin{array}{c}\text { First } \\
\text { month }\end{array}$ & $\begin{array}{l}\text { Second } \\
\text { month }\end{array}$ & $\begin{array}{l}\text { Third } \\
\text { month }\end{array}$ & $\begin{array}{c}\text { Four } \\
\text { month }\end{array}$ & $\begin{array}{c}\text { Five } \\
\text { month }\end{array}$ & $\begin{array}{c}\text { Six } \\
\text { month }\end{array}$ & $\begin{array}{l}\text { Seven } \\
\text { month }\end{array}$ & $\begin{array}{l}\text { Eight } \\
\text { month }\end{array}$ & $\begin{array}{l}\text { Nine } \\
\text { month }\end{array}$ & $\begin{array}{c}\text { Ten } \\
\text { month }\end{array}$ & Notes \\
\hline 1 & $128 / 73$ & $130 / 80$ & $111 / 71$ & $110 / 80$ & $111 / 80$ & $110 / 80$ & $110 / 82$ & $120 / 82$ & $120 / 82$ & $120 / 82$ & $120 / 82$ & \\
\hline 2 & $140 / 88$ & $136 / 90$ & & & & & & & & & & dropped \\
\hline 3 & $150 / 100$ & $150 / 100$ & $149 / 100$ & $148 / 100$ & $140 / 100$ & $150 / 100$ & $146 / 100$ & $140 / 100$ & $148 / 100$ & $155 / 100$ & $149 / 100$ & \\
\hline 4 & $136 / 72$ & $138 / 80$ & $130 / 80$ & $130 / 80$ & $130 / 80$ & $130 / 80$ & $130 / 80$ & $130 / 80$ & $130 / 80$ & $130 / 80$ & $130 / 80$ & \\
\hline 5 & $110 / 70$ & $130 / 92$ & $130 / 92$ & $130 / 92$ & $130 / 95$ & $130 / 95$ & $130 / 95$ & $130 / 95$ & $130 / 95$ & $130 / 95$ & $130 / 95$ & \\
\hline 6 & $128 / 88$ & $128 / 88$ & $130 / 88$ & $130 / 88$ & $130 / 90$ & $130 / 90$ & $130 / 90$ & $130 / 88$ & $130 / 88$ & $130 / 88$ & $130 / 88$ & \\
\hline 7 & $160 / 90$ & $160 / 90$ & $150 / 95$ & $150 / 90$ & $150 / 95$ & $150 / 90$ & $150 / 90$ & $150 / 90$ & $150 / 90$ & $150 / 90$ & $150 / 90$ & \\
\hline 8 & $129 / 87$ & $129 / 88$ & $130 / 85$ & $130 / 85$ & $130 / 87$ & $130 / 87$ & $130 / 87$ & $130 / 87$ & $130 / 87$ & $130 / 87$ & $130 / 87$ & \\
\hline 9 & $160 / 80$ & $160 / 79$ & $140 / 80$ & $140 / 60$ & $140 / 80$ & $140 / 80$ & $140 / 80$ & $150 / 80$ & $150 / 80$ & $150 / 80$ & $150 / 80$ & \\
\hline 10 & $134 / 86$ & $134 / 86$ & $140 / 90$ & & & & & & & & & dropped \\
\hline 11 & $128 / 77$ & $130 / 80$ & $120 / 80$ & $120 / 80$ & $125 / 80$ & $125 / 80$ & $120 / 80$ & $120 / 77$ & $120 / 88$ & $133 / 85$ & $140 / 90$ & \\
\hline 12 & $120 / 80$ & $120 / 70$ & $130 / 80$ & $130 / 80$ & $135 / 85$ & $135 / 80$ & $135 / 80$ & $135 / 80$ & $130 / 80$ & $130 / 80$ & $130 / 80$ & \\
\hline 13 & $140 / 90$ & $140 / 90$ & $140 / 90$ & $140 / 90$ & $140 / 90$ & $140 / 92$ & $140 / 92$ & $140 / 92$ & $140 / 92$ & $140 / 92$ & $140 / 92$ & \\
\hline 14 & $130 / 80$ & $130 / 80$ & $140 / 90$ & $140 / 90$ & $140 / 92$ & $140 / 92$ & $140 / 92$ & $140 / 92$ & $140 / 92$ & $140 / 92$ & $140 / 92$ & \\
\hline 15 & $133 / 66$ & $133 / 66$ & $140 / 80$ & $140 / 80$ & $140 / 80$ & $140 / 80$ & $140 / 80$ & $140 / 80$ & $140 / 85$ & $140 / 85$ & $140 / 85$ & \\
\hline 16 & $120 / 70$ & $160 / 50$ & $150 / 90$ & $150 / 90$ & $150 / 90$ & $150 / 90$ & $150 / 90$ & $150 / 90$ & $150 / 90$ & $150 / 90$ & $150 / 90$ & \\
\hline 17 & $138 / 79$ & $138 / 79$ & $140 / 92$ & $140 / 90$ & $140 / 90$ & $140 / 90$ & $140 / 92$ & $140 / 92$ & $140 / 92$ & $140 / 92$ & $140 / 90$ & \\
\hline 19 & $140 / 80$ & $140 / 80$ & $140 / 92$ & $140 / 92$ & $140 / 95$ & $140 / 95$ & $140 / 95$ & $140 / 95$ & $140 / 95$ & $140 / 95$ & $140 / 95$ & \\
\hline 20 & $140 / 85$ & $140 / 87$ & $140 / 90$ & $140 / 80$ & $140 / 85$ & $140 / 85$ & $140 / 85$ & $140 / 90$ & $140 / 90$ & $140 / 90$ & $140 / 90$ & \\
\hline
\end{tabular}




\section{Continued}

\begin{tabular}{|c|c|c|c|c|c|c|c|c|c|c|c|c|}
\hline 21 & $139 / 78$ & $140 / 80$ & $139 / 78$ & $139 / 75$ & $140 / 80$ & $139 / 80$ & $139 / 80$ & $130 / 80$ & $140 / 88$ & $140 / 88$ & $140 / 87$ & \\
\hline 22 & $157 / 100$ & $155 / 100$ & $157 / 100$ & $157 / 105$ & $156 / 100$ & $140 / 105$ & $150 / 100$ & $150 / 100$ & $150 / 100$ & $150 / 100$ & $150 / 100$ & \\
\hline 23 & $160 / 100$ & $160 / 100$ & $160 / 105$ & $160 / 110$ & $160 / 100$ & $150 / 100$ & $150 / 100$ & $150 / 100$ & $150 / 100$ & $150 / 105$ & $150 / 105$ & \\
\hline 24 & $140 / 80$ & $140 / 80$ & $140 / 80$ & $140 / 85$ & $140 / 85$ & $140 / 85$ & $140 / 90$ & $140 / 88$ & $140 / 90$ & $140 / 90$ & $140 / 90$ & \\
\hline 25 & $160 / 99$ & $160 / 100$ & $169 / 99$ & $160 / 98$ & $160 / 105$ & $160 / 100$ & $160 / 98$ & $160 / 100$ & $160 / 98$ & $150 / 100$ & $150 / 100$ & \\
\hline 26 & $130 / 80$ & $130 / 82$ & $130 / 80$ & $130 / 80$ & $130 / 85$ & $130 / 86$ & $130 / 86$ & $130 / 88$ & $136 / 90$ & $130 / 88$ & $133 / 90$ & \\
\hline 27 & $140 / 90$ & $140 / 90$ & $140 / 95$ & $140 / 95$ & $140 / 95$ & $140 / 95$ & $145 / 95$ & $150 / 95$ & $150 / 90$ & $150 / 95$ & $150 / 95$ & \\
\hline 28 & $160 / 100$ & $160 / 100$ & $160 / 105$ & $160 / 100$ & & & & & & & & dropped \\
\hline 29 & $130 / 80$ & $130 / 80$ & $130 / 80$ & $135 / 80$ & $140 / 80$ & $140 / 85$ & $140 / 85$ & $140 / 85$ & $140 / 85$ & $140 / 85$ & $140 / 85$ & \\
\hline 30 & $150 / 96$ & $150 / 96$ & $155 / 100$ & $155 / 100$ & $155 / 100$ & $155 / 100$ & $155 / 100$ & $155 / 100$ & $155 / 100$ & $155 / 100$ & $155 / 100$ & \\
\hline 31 & $150 / 96$ & $150 / 96$ & $155 / 100$ & $155 / 100$ & $155 / 100$ & $155 / 100$ & $155 / 100$ & $150 / 98$ & $150 / 98$ & $155 / 100$ & $155 / 100$ & \\
\hline 32 & $130 / 80$ & $130 / 82$ & $130 / 82$ & $130 / 82$ & $130 / 82$ & $130 / 85$ & $130 / 85$ & $140 / 90$ & $140 / 90$ & $140 / 90$ & $140 / 90$ & \\
\hline 33 & $138 / 80$ & $130 / 82$ & $130 / 82$ & $130 / 82$ & $130 / 82$ & $130 / 85$ & $130 / 85$ & $140 / 90$ & $140 / 90$ & $140 / 90$ & $140 / 90$ & \\
\hline 34 & $150 / 90$ & & & & & & & & & & & dropped \\
\hline 35 & $140 / 88$ & $140 / 88$ & $140 / 88$ & $140 / 90$ & $140 / 90$ & $140 / 90$ & $140 / 90$ & $140 / 90$ & $140 / 90$ & $140 / 90$ & $140 / 90$ & \\
\hline 36 & $140 / 80$ & $140 / 88$ & $140 / 88$ & $140 / 90$ & $140 / 90$ & $140 / 90$ & $140 / 90$ & $140 / 90$ & $140 / 90$ & $140 / 90$ & $140 / 90$ & \\
\hline 37 & $160 / 90$ & $157 / 93$ & & & & & & & & & & dropped \\
\hline 38 & $140 / 88$ & $140 / 88$ & $145 / 90$ & $145 / 90$ & $145 / 90$ & $145 / 90$ & $145 / 90$ & $140 / 90$ & $140 / 90$ & $140 / 95$ & $145 / 90$ & \\
\hline 39 & $140 / 88$ & $140 / 88$ & $145 / 90$ & $145 / 90$ & $145 / 90$ & $145 / 90$ & $145 / 90$ & $140 / 90$ & $140 / 90$ & $140 / 95$ & $140 / 95$ & \\
\hline 40 & $150 / 90$ & $150 / 90$ & $150 / 90$ & $155 / 90$ & $155 / 92$ & $155 / 92$ & $155 / 92$ & $155 / 92$ & $155 / 92$ & $155 / 90$ & $155 / 92$ & \\
\hline 41 & $150 / 90$ & $150 / 90$ & $150 / 90$ & $155 / 90$ & $155 / 92$ & $155 / 92$ & $155 / 92$ & $155 / 92$ & $155 / 92$ & $140 / 90$ & $155 / 92$ & \\
\hline 42 & $140 / 88$ & $145 / 90$ & $145 / 90$ & $145 / 90$ & $145 / 95$ & $145 / 95$ & $145 / 90$ & $140 / 90$ & $140 / 90$ & $140 / 90$ & $140 / 90$ & \\
\hline 43 & $140 / 88$ & $145 / 90$ & $145 / 90$ & $145 / 90$ & $145 / 95$ & $145 / 95$ & $145 / 90$ & $140 / 90$ & $140 / 90$ & $140 / 90$ & $140 / 90$ & \\
\hline 44 & $140 / 88$ & $150 / 88$ & $150 / 85$ & $150 / / 85$ & $150 / 88$ & $150 / 88$ & $150 / 88$ & $155 / 88$ & $155 / 88$ & $155 / 88$ & $155 / 88$ & \\
\hline 45 & $145 / 98$ & $140 / 100$ & & & & & & & & & & dropped \\
\hline 46 & $160 / 90$ & $160 / 92$ & $160 / 99$ & $160 / 94$ & $160 / 90$ & $160 / 92$ & $160 / 92$ & $160 / 90$ & $150 / 93$ & $163 / 93$ & $156 / 98$ & \\
\hline 47 & $150 / 90$ & $150 / 90$ & $155 / 92$ & $155 / 92$ & $160 / 95$ & $160 / 95$ & $160 / 95$ & $160 / 95$ & $163 / 96$ & $160 / 95$ & $160 / 95$ & \\
\hline 48 & $160 / 90$ & $160 / 92$ & $160 / 90$ & $160 / 90$ & $160 / 90$ & $160 / 92$ & $160 / 92$ & $160 / 90$ & $160 / 92$ & $160 / 92$ & $160 / 92$ & \\
\hline 49 & $150 / 98$ & $160 / 100$ & $160 / 105$ & & & & & & & & & dropped \\
\hline 50 & $150 / 96$ & $150 / 90$ & $155 / 92$ & $155 / 92$ & $160 / 95$ & $160 / 94$ & $159 / 93$ & $157 / 98$ & $160 / 92$ & $163 / 98$ & $154 / 100$ & \\
\hline
\end{tabular}

